\title{
Liquid phase hydrodechlorination of dieldrin and DDT over Pd/C and Raney-Ni
}

\author{
Sergei S. Zinovyev ${ }^{\mathrm{a}}$, Natalia A. Shinkova ${ }^{\mathrm{a}, \mathrm{b}, 1}$, Alvise Perosa ${ }^{\mathrm{a}}$, Pietro Tundo ${ }^{\mathrm{b}, *}$ \\ anteruniversity Consortium "Chemistry for the Environment" (INCA), Dorsoduro 2137, 30123 Venezia, Italy \\ ${ }^{\mathrm{b}} \mathrm{Ca}$ ' Foscari University of Venice, Dorsoduro 2137, 30123 Venezia, Italy
}

Received 5 February 2004; received in revised form 24 June 2004; accepted 28 June 2004

Available online 9 September 2004

\begin{abstract}
Selectivity and product distribution of hydrodechlorination (HDCl) of dieldrin and DDT are studied in different liquid phase systems, namely in: (1) in ethanol; and (2) in the supported ionic liquid heterogeneous catalytic system (multiphase system), composed by the organic phase and aqueous $\mathrm{KOH}$, a quaternary ammonium ionic liquid promoter (Aliquat 336), and a metal catalyst, e.g. 5\% Pd/C, 5\% Pt/C, or RaneyNi. At $50{ }^{\circ} \mathrm{C}$ and atmospheric pressure of hydrogen, a quantitative hydrodechlorination of DDT in the biphasic system with ionic liquid layer is achieved in $40 \mathrm{~min}$ and in $4 \mathrm{~h}$ with Raney-Ni and $\mathrm{Pd} / \mathrm{C}$, respectively, while the reaction on $\mathrm{Pt} / \mathrm{C}$ or on $\mathrm{Pd} / \mathrm{C}$ without Aliquat 336 is slow. Dieldrin undergoes partial dechlorination, with high selectivity achievable only for its mono- and bi-dechlorination products. Dechlorination pathways and reactivity of different types of organic chlorine atoms versus the catalyst nature and other conditions are discussed.

(C) 2004 Elsevier B.V. All rights reserved.
\end{abstract}

Keywords: Dieldrin; DDT; Hydrodechlorination; Detoxification; Multiphase system; Supported ionic liquid; Aliquat 336; Pd/C; Pt/C; Raney-Ni

\section{Introduction}

Considerable stockpiles of persistent organic pollutants (POPs) exist in the world, such as for example, pesticides that have been banned from use. In many of the more industrialized nations, POP wastes are routinely burnt in incinerators. However, there is concern that these opensystem technologies generate levels of POP emissions through either incomplete combustions or transformations into new POPs, such as dioxins and furans. Over last 10-15 years, a number of non-combustion technologies have been demonstrated to effectively treat POPs wastes in countries such as Canada, USA, Australia, and Japan. Some methods are outlined by UNEP [1].

The catalytic hydrogenolysis of organochlorine compounds (hydrodechlorination, $\mathrm{HDCl}$ ) [2] is a viable, low-

\footnotetext{
* Corresponding author. Tel.: +39041 2348642; fax: +390412348620

E-mail address: tundop@unive.it (P. Tundo).

${ }^{1}$ On leave from the N.D. Zelinsky Institute of Organic Chemistry of Russian Academy of Sciences, Leninsky pr. 47, Moscow 119991, Russia.
}

cost, and green methodology with a potential to be employed for degradation of the hazardous polychlorinated aromatics and aliphatics, such as polychlorinated benzenes, chlorophenols, halogenated C1-C3 hydrocarbons, PCBs, pesticides, and dioxins. The $\mathrm{HDCl}$ reaction in the liquid [3] and gas phase [4] is being intensively studied nowadays.

The multiphase system for $\mathrm{HDCl}$ is based on the liquid phase methodology, where the alkali (usually $\mathrm{KOH}$ ) is present in a separate aqueous liquid layer, and the polychlorinated substrate is present in a hydrocarbon solvent (usually isooctane). The separation of reagent and alkali is advantageous since it makes it easier to recover the reaction products, but needs a promoter to bring the alkali and the reagents to the catalyst surface. This promoter was found to be a quaternary ammonium salt, e.g. the commercially available and widely used in phase-transfer catalysis Aliquat 336. Its presence not only makes the reaction possible and with no sensible sign of catalyst deactivation (normally the reaction simply does not proceed in a biphasic aqueous organic system without quaternary salt), but also renders the $\mathrm{HDCl}$ process faster than in alcoholic base systems. The role 
of Aliquat 336 in this system is intriguing also because it opens up possibilities to vary the reaction selectivity in the reduction of multiple functional groups [5] and to use catalysts, which seemed to be almost inactive in this reaction (e.g. the use of non-expensive Raney-Ni in dechlorination of polychlorinated substrates [6]).

Recently, we have reported on the $\mathrm{HDCl}$, dehydrochlorination, and reductive dechlorination of lindane under the multiphase conditions [7], and formerly, on a number of applications of the multiphase catalytic systems in $\mathrm{HDCl}$ of chlorinated aromatics $[6,8,9]$ and other reduction reactions [5]. The POPs, such as PCBs [9] and dioxins [10] have been also reduced quantitatively over $\mathrm{Pd} / \mathrm{C}$ under these conditions. It has been noticed that changes in the catalyst nature and composition of the system may substantially affect the reaction mechanism and selectivity. In addition, it appears that the aliphatic chlorides may behave in an absolutely different way [7] than the aromatic ones, which have been studied in abundance previously $[6,8,9]$. Tuning the multiphase system composition usually allows one to change reaction selectivity towards one or another product or to achieve more efficient dechlorination.

We extend the study of liquid phase $\mathrm{HDCl}$, and particularly of the multiphase one, to two other examples of polychlorinated hazards, dieldrin and DDT, which are 1,2,3,4,10,10-hexachloro-6,7-epoxy-1,4,4 $\alpha, 5,6,7,8,8 \alpha$ octahydro-1,4-endo,exo-5,8-dimethanonaphthalene and 1,1'-bis(4-chlorophenyl)-2,2,2-trichloroethane, respectively (see Fig. 1). These two substances are new objects of study of $\mathrm{HDCl}$ under multiphase conditions and are the widely used pesticides, which are very toxic, and the use and production of which has been banned in most developed countries.

Dieldrin belongs to the 12 POPs and, together with other "drin" group pesticides, e.g. aldrin and endrin, was formerly used extensively as insecticide on crops, such as corn and cotton. There are very few data on the transformations of "drins" or DDT in catalytic reduction systems. The known techniques for dieldrin (or other "drins") dechlorination refer mainly to the photolysis [11], hydrolysis [12], or reduction under harsh reduction conditions, e.g. using metallic sodium [13], lithium and tert-butanol [14], etc. which nevertheless, except the latter method, afford only partial dechlorination.
DDT (or $p, p^{\prime}$-DDT) [15] used to be a broadly used insecticide which has been banned in all the developed countries since seventies but is still used in the Third World. There are a number of studies reporting on phytoremediation [16] and bioremediation [17] of DDT. Reductive catalytic methods have been also reported, e.g. with $\mathrm{Pd} / \mathrm{Mg}$ bimetallic particles [18], via electrolytic [19], or photosensitized reductive dechlorination methods [20]. A number of studies on the non-catalytic reductive dechlorination of DDT have been also reported [21], which however do not give complete dechlorination. To the best of our knowledge, the studies on the catalytic $\mathrm{HDCl}$ of DDT over supported catalysts, with a single exception [22], are unknown.

The present study focuses on the investigation of possibilities of reductive catalytic dechlorination of dieldrin and DDT in order to identify the alternative (other than combustion) ways of their disposal/utilization; on the other hand, it pursues also the scientific goal of exploration of chemical behavior of different types of organic chlorines and related selectivity issues in different systems.

\section{Experimental}

All the reagents and solvents were used as purchased without further purification. Raney-Ni (50\% slurry in water) was from Engelhard, Actimet $\mathrm{M}^{\mathrm{TM}}(\mathrm{Ni} 93 \%$ and $\mathrm{Al} 7 \%$, particle size distribution of $0-80 \mu \mathrm{m}$, surface area of 70 $80 \mathrm{~m}^{2} / \mathrm{g}$ ). $5 \% \mathrm{Pd} / \mathrm{C}$ was from Aldrich, Art. No. 20,568-0. 5\% $\mathrm{Pt} / \mathrm{C}$ was from Fluka, Art. No. 80982. Dieldrin (1,2,3,4, 10,10-hexachloro-6,7-epoxy-1,4,4 $\alpha, 5,6,7,8,8 \alpha$-octahydro1,4-endo,exo-5,8-dimethanonaphthalene, $90 \%$ pure), Aliquat $336^{\circledR}$ (tricaprylmethylammonium chloride), and DDT (1,1'-bis-(4-chlorophenyl)-2,2,2-trichloroethane, 99\% pure) were from Aldrich. GC analyses were performed on a Varian 3400 using a fused silica capillary column "Chrompack CPSil 24 CB lowbleed/MS" $(30 \mathrm{~m} \times 0.25 \mathrm{~mm}$, film thickness $0.25 \mu \mathrm{m})$. GC/MS analyses were performed on an Agilent 5973 mass detector coupled to an Agilent 6890N GC with an HP-5MS capillary column $(30 \mathrm{~m} \times 0.25 \mathrm{~mm}$, film thickness $0.25 \mu \mathrm{m})$.

A $25 \mathrm{~mL}$ three-necked round-bottomed reactor with a water jacket, supplied with a tube for hydrogen supply, a condenser was loaded with $10 \mathrm{~mL}$ isooctane/toluene (1:1 (v/v),

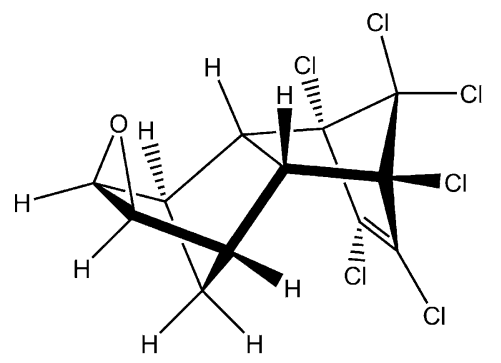

Dieldrin<smiles>Clc1ccc(C(c2ccc(Cl)cc2)C(Cl)(Cl)Cl)cc1</smiles>

DDT

Fig. 1. 
dieldrin is not well soluble in isooctane) solution of $0.267 \mathrm{~g}$ $(0.7 \mathrm{mmol})$ of dieldrin or $10 \mathrm{~mL}$ isooctane solution of $0.248 \mathrm{~g}(0.7 \mathrm{mmol})$ of DDT, $0.059 \mathrm{~g}$ of $n$-dodecane $(0.35 \mathrm{mmol})$ as the GC internal standard and, where indicated (see tables), $0.103 \mathrm{~g}(0.26 \mathrm{mmol})$ of Aliquat 336 , and containing $0.0455 \mathrm{~g}$ of $5 \% \mathrm{Pd} / \mathrm{C}(0.02 \mathrm{mmol} \mathrm{Pd})$ or $0.25 \mathrm{~g}$ of the Raney-Ni slurry ( $2 \mathrm{mmol} \mathrm{Ni}$ ) or $0.0837 \mathrm{~g}$ of $5 \%$ $\mathrm{Pt} / \mathrm{C}(0.02 \mathrm{mmol} \mathrm{Pt}) .5 .7 \mathrm{~mL}$ of the aqueous $\mathrm{KOH}$ solution was added therein, if isooctane/toluene was the organic phase. In case of the reactions in $\mathrm{EtOH}, 10 \mathrm{ml}$ solution of all of the above, save Aliquat 336, containing the catalyst and including $\mathrm{KOH}$, in absolute ethanol was used instead.

All the components loaded, the reaction was stirred magnetically at $1000 \mathrm{rpm}$, and thermostated at $50 \pm 1{ }^{\circ} \mathrm{C}$, while bubbling $\mathrm{H}_{2}$ at atmospheric pressure $(10 \mathrm{~mL} / \mathrm{min})$.

The samples were collected from the organic phase at time intervals, and analysed by GC and GC/MS. About $20 \mu \mathrm{L}$ of the reaction mixture was taken for each sample, which was then diluted with ethyl ether up to 1-2 ml, or with ethanol if this was the solvent. Before injection, the samples were shaken with silica to remove Aliquat 336, and/or filtered through the Whatman filter to remove catalyst. The samples in ethanol (dieldrin reactions), where $\mathrm{KOH}$ was present, were shaken with the diethyl ether-water mixture, and the ether layer was then analyzed.

Quantitative analyses of reaction mixtures were performed by referring the analyzed compound peak area to that of the internal standard, and using the same calibration coefficient for products as that for the substrate. Alternatively (e.g. in EtOH systems where dodecane is insoluble), the content of the mixture was calculated as percent ratio of areas of MS total ion peaks of the analyzed compounds. In case of GC or GC/MS analyses of dieldrin reactions, the product ratios reported in the tables are expressed as \% of the total amount of products, arising from dieldrin reduction. The content of DDT products was normalized to $100 \%$ for convenience, given that no other byproducts were observed. Thus, the concentrations reported in tables for both the dieldrin and DDT reactions, are meant to be $\%$ of the initial substrate amount.

The $X$ value reported in tables is the dechlorination degree, which is calculated as follows:

$$
\begin{aligned}
& X= 1-\frac{\sum_{i=0}^{j} i C_{i}}{j C^{0}} \\
& \times 100 \%(\text { or reported total } \% \text { of components })
\end{aligned}
$$

where $C_{i}$ is the molar concentration of a substrate containing $i$ chlorine atoms in the molecule, $j$ the initial number of chlorine atoms in the molecule, and $C^{0}$ the initial concentration of the dechlorinated compound. For dieldrin experiments, where the mass balance of products was normally lower than $100 \%$, the $X$ value was normalized to the actual \% of mixture components.

\section{Results and discussion}

Three different catalysts were studied for the $\mathrm{HDCl}$ of dieldrin: $5 \% \mathrm{Pd} / \mathrm{C}$ (Aldrich), 5\% Pt/C (Aldrich), and Raney-Ni (50\% slurry in water, Engelhard). The multiphase reaction system (isooctane/toluene-aqueous $\mathrm{KOH}$ ) and ethanol $\mathrm{KOH}$ solution were used as reaction media. The reactions were run with different concentrations of $\mathrm{KOH}$, and either in the presence or in the absence of Aliquat 336 (tricaprylmethylammonium chloride) in the multiphase system. The products were monitored by GC/ MS. Additional structural information was obtained from the NMR analyses of the pure products.

\subsection{Hydrodechlorination of dieldrin over $5 \% \mathrm{Pd} / \mathrm{C}$}

In the biphasic isooctane/toluene-7\% aqueous $\mathrm{KOH}$ system, in the presence of Aliquat 336, complete conversion of dieldrin to the mono-dechlorination product $\mathbf{2}$ is achieved in 14 min (entry 1, Table 1). Further reduction is slower and less selective, and the products corresponding to the substitution of three (3) and four (4) chlorines with hydrogen are formed at the same time, as indicated by the MS spectra. The same reaction in the absence of Aliquat 336 proceeds very slowly (entry 2), and the full conversion of dieldrin requires almost $4 \mathrm{~h}$. No reaction was observed in the $\mathrm{Pd} / \mathrm{C}$ system without $\mathrm{KOH}$ (isooctane-water) (Scheme 1).

Product 2 was separated and analyzed by ${ }^{1} \mathrm{H}$ NMR, which confirmed the presence of the proton on the carbon bridge, giving a singlet at $\delta 4.3$, in agreement with published data [23]. The position of the proton in $\mathbf{2}$ was determined based on the NOESY spectrum of $\mathbf{6}$, the product of further reduction of $\mathbf{2}$ (see Scheme 3) in the reaction with Raney-Ni, described below.

Based on the GC/MS spectra of the intermediates and products arising from the reduction of dieldrin, only the number of chlorine atoms removed can be estimated, not their positions. However, some hypotheses can be made based on the composition of the reaction mixture. Along with the $\mathrm{HDCl}$ steps $(-\mathrm{Cl},+\mathrm{H})$, the addition of two extra protons took place in some cases. This can correspond either to the $\mathrm{C}=\mathrm{C}$ bond hydrogenation or to the hydrogenolysis of the epoxy ring. The addition of these two protons occurred

Table 1

Hydrodechlorination of dieldrin over $5 \% \mathrm{Pd} / \mathrm{C}$ in isooctane/toluene-7\% aqueous $\mathrm{KOH}$

\begin{tabular}{llllllrr}
\hline No. & Aliquat 336 & Time (min) & Conversion (\%) & $X(\%)$ & \multicolumn{3}{c}{ Yield $(\%, \mathrm{GC})$} \\
\cline { 5 - 8 } & & & & & $\mathbf{2}$ & $\mathbf{3}$ & $\mathbf{4}$ \\
\hline 1 & Yes & 14 & 100 & 27 & 77 & 5 & 12 \\
& & 380 & & 42 & 34 & 38 & 15 \\
2 & \multirow{2}{*}{ No } & 140 & 74 & 24 & 49 & 7 & 3 \\
& 230 & 100 & 34 & 70 & 12 & 4 \\
& 430 & & 38 & 54 & 29 & 8 \\
\hline
\end{tabular}



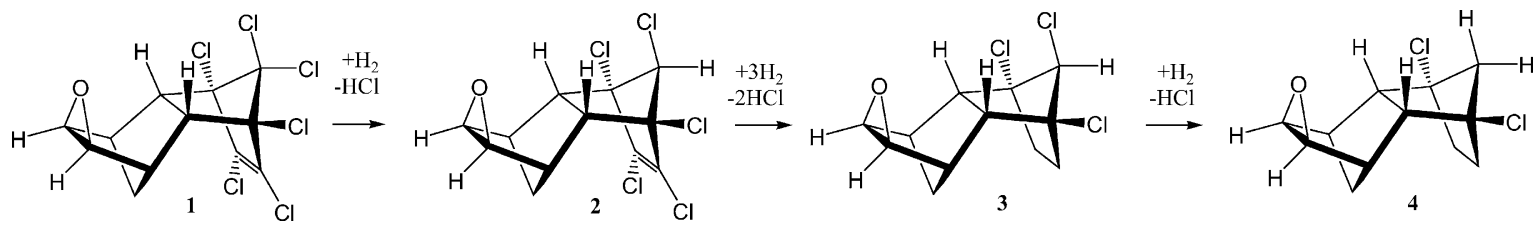

Scheme 1. Hydrodechlorination of dieldrin over $5 \% \mathrm{Pd} / \mathrm{C}$ in the isooctane-aqueous $\mathrm{KOH}$ multiphase system.

only in the products where three or more chlorines had been already reduced. This fact may be indicative of the $\mathrm{C}=\mathrm{C}$ bond hydrogenation, since it is well-known that the double bond between two chlorinated carbons must be first dechlorinated before it can be reduced, except some particular cases [24]. In addition no evidence of $\mathrm{H}_{2}$ addition as the initial step was seen, which likely excludes epoxide opening.

In $\mathbf{2}$, the reduction of the double bond chlorines and double bond hydrogenation are not kinetically distinguishable. The hydrogenation of the double bond follows rapidly, since the product corresponding to three chlorines removal without reduction of double bond was not found by GC/MS.

Thus, it can be deduced that the mono-dechlorination product 2 in the biphasic system undergoes the removal of two chlorines at the $\mathrm{C}=\mathrm{C}$ bond and the hydrogenation of the latter, and the resulting tri-dechlorination product $\mathbf{3}$ then undergoes one more step of $\mathrm{HDCl}$ to 4 . No products with the molecular ion masses corresponding to the removal of more than four chlorine atoms were observed. The two remaining chlorines are probably those at the bridgehead carbons, which are less reactive. In fact, the chlorines at bridgehead carbons are not likely to undergo nucleophilic substitution (neither $\mathrm{S}_{\mathrm{N}} 2$, which is impossible sterically, nor $\mathrm{S}_{\mathrm{N}} 1$ which require the flat geometry of carbocation), but theoretically may only be reduced via the radical mechanism.
In the same multiphase system with Aliquat 336 but in presence of the concentrated aqueous $\mathrm{KOH}$ (Table 2, entry 1) dieldrin reacts in a more complicated and less selective manner. The mono-dechlorination product $\mathbf{2}$, once formed, in addition to product $\mathbf{3}$ observed in the previous case, gives also a product, whose MS spectrum and retention time correspond to $\mathbf{6}$ (separated in the reaction with Raney-Ni, see below), the product deriving from $\mathrm{HDCl}$ of two chlorines. The products corresponding to the $\mathrm{HDCl}$ of four chlorines and saturation of the double bond appeared to be two in this case, present in nearly the same content, of which one (4) is the same as that observed in the system with the diluted base, discussed previously. It can be suggested, that in addition to the previously suggested pathway 1-2-3-4, the pathway 1-26-7 takes place in this case (see Scheme 2).

Comparing data in Tables 1 and 2 one can see that generally higher yields of the products of deeper dechlorination have been obtained in shorter reaction times in the reaction of dieldrin on $\mathrm{Pd} / \mathrm{C}$ in ethanol. $\mathrm{HDCl}$ of the first chlorine to 2 takes place in just $10 \mathrm{~min}$ after which the reaction follows nearly the same pathway as in the multiphase system with concentrated $\mathrm{KOH}$, but gives two different products corresponding to the reduction of two chlorines (by MS one is $\mathbf{6}$ and the other possibly has the structure of 5). The reaction gives the products of the reduction of four chlorines and the double bond ( 4 found in

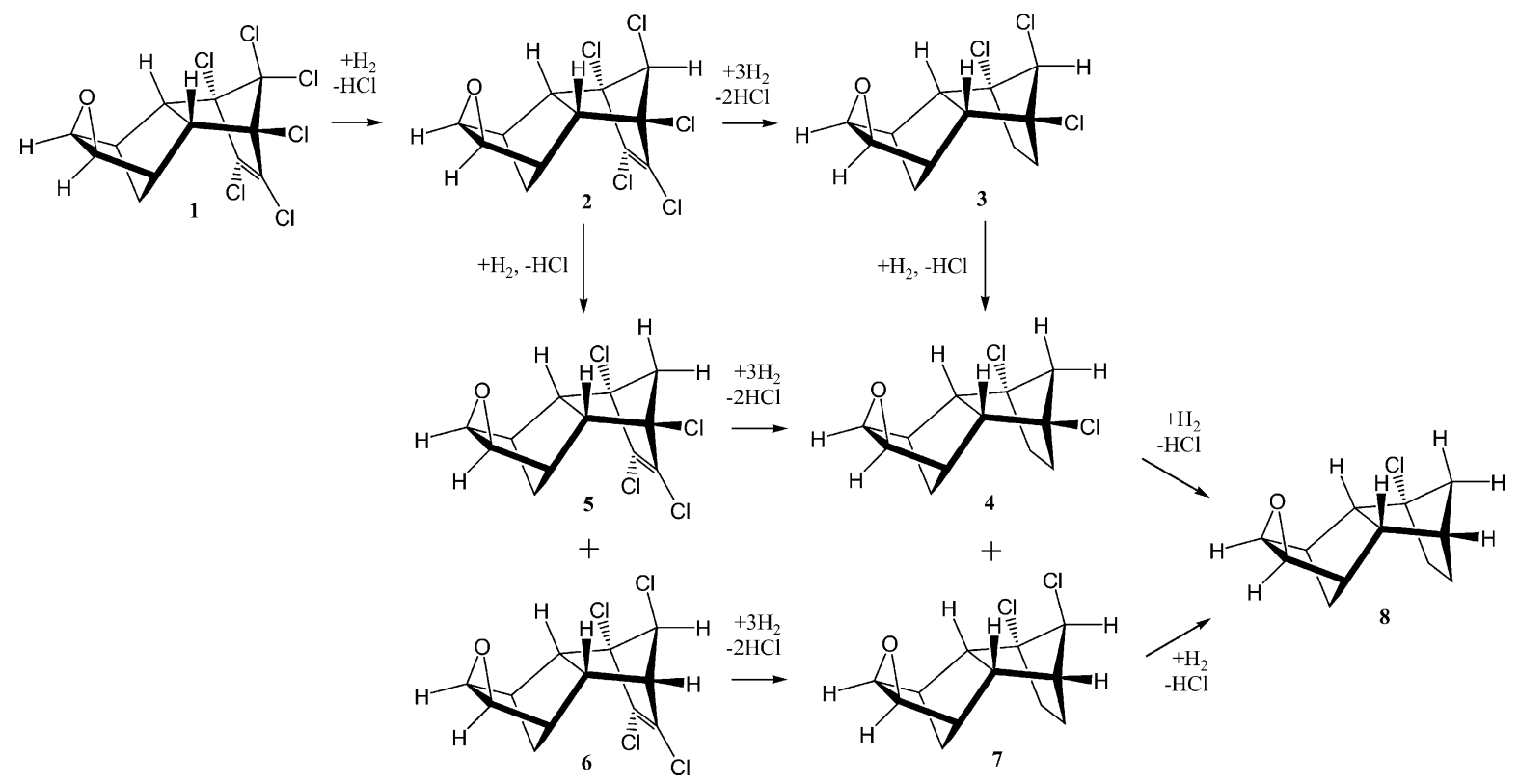

Scheme 2. Suggested scheme of dieldrin $\mathrm{HDCl}$ over $5 \% \mathrm{Pd} / \mathrm{C}$ in the isooctane/toluene-concentrated $\mathrm{KOH}$ and ethanolic $\mathrm{KOH}$ systems. 

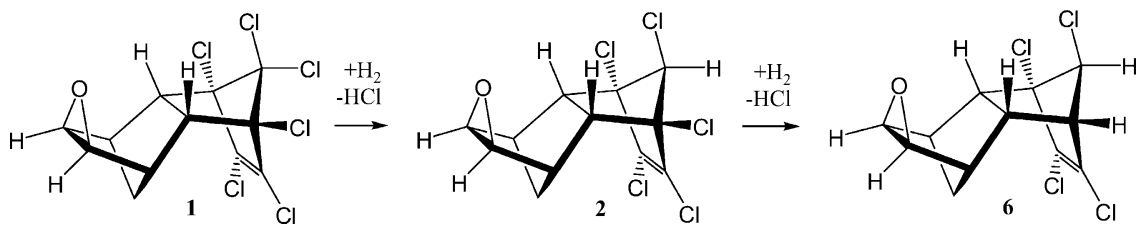

Scheme 3. Hydrodechlorination of dieldrin over Raney-Ni.

Table 2

Hydrodechlorination of dieldrin over $5 \% \mathrm{Pd} / \mathrm{C}$ in different systems

\begin{tabular}{|c|c|c|c|c|c|c|c|c|c|c|c|}
\hline \multirow[t]{2}{*}{ No. } & \multirow[t]{2}{*}{ Solvent } & \multirow[t]{2}{*}{$\mathrm{KOH}(\%)$} & \multirow[t]{2}{*}{ Aliquat 336} & \multirow[t]{2}{*}{ Time (min) } & \multirow[t]{2}{*}{ Conversion (\%) } & \multirow[t]{2}{*}{$X(\%)$} & \multicolumn{5}{|c|}{ Yield $(\%, \mathrm{GC})$} \\
\hline & & & & & & & 2 & $5+6$ & 3 & $4+7$ & 8 \\
\hline 1 & Isooctane/toluene & $50 \mathrm{aq}$. & Yes & $\begin{array}{r}50 \\
290\end{array}$ & 100 & $\begin{array}{l}26 \\
34\end{array}$ & $\begin{array}{l}78 \\
48\end{array}$ & $\begin{array}{r}4^{\mathrm{a}} \\
16^{\mathrm{a}}\end{array}$ & $\begin{array}{r}4 \\
19\end{array}$ & $\begin{array}{r}8 \\
11\end{array}$ & $\begin{array}{l}0 \\
0\end{array}$ \\
\hline 2 & $\mathrm{EtOH}$ & 7 & No & $\begin{array}{r}10 \\
195\end{array}$ & $\begin{array}{r}97 \\
100\end{array}$ & $\begin{array}{l}23 \\
43\end{array}$ & $\begin{array}{l}79 \\
30\end{array}$ & $\begin{array}{l}4 \\
4\end{array}$ & $\begin{array}{r}6 \\
27\end{array}$ & $\begin{array}{r}5 \\
25\end{array}$ & $\begin{array}{l}0 \\
6\end{array}$ \\
\hline 3 & $\mathrm{EtOH}$ & 36 & No & $\begin{array}{r}30 \\
900\end{array}$ & 100 & $\begin{array}{l}27 \\
53\end{array}$ & $\begin{array}{r}77 \\
2\end{array}$ & $\begin{array}{r}3 \\
12\end{array}$ & $\begin{array}{r}4 \\
36\end{array}$ & $\begin{array}{r}3 \\
35\end{array}$ & $\begin{array}{l}0 \\
3\end{array}$ \\
\hline
\end{tabular}

${ }^{\mathrm{a}} 6$ only.

excess). Finally, a small amount of the product corresponding to the $\mathrm{HDCl}$ of five chlorines and the double bond hydrogenation was observed in the ethanolic system, which must possess the structure of $\mathbf{8}$, as indicated on Scheme 2 . The reaction profiles of dieldrin reduction in $36 \%$ ethanol $\mathrm{KOH}$ solution are represented in Fig. 2 (see also entry 3). The concentration of $\mathrm{KOH}$ in ethanol seems not to be critical, even though faster reaction is observed in a diluted solution (entry 2). Thus, in the systems with ethanolic base or in the presence of concentrated aqueous base dieldrin undergoes deeper and less selective reduction on $\mathrm{Pd} / \mathrm{C}$, where all the steps of Scheme 2 appear feasible. In other words, all types of chlorines react, though, no complete dechlorination was observed even after a very long reaction time, probably due to the catalyst deactivation (see Fig. 2). Other dechlorination products of dieldrin observed by $\mathrm{GC} /$ MS, formed via different pathways, were present in small amount (usually less than 10\%).

It is worth mentioning that reduction of the chlorine in the bridge (10 position) of dieldrin to give 2 , which is the fastest in all the systems with $\mathrm{Pd} / \mathrm{C}$ studied herein, is rather unusual. According to the two independent studies on the reduction of

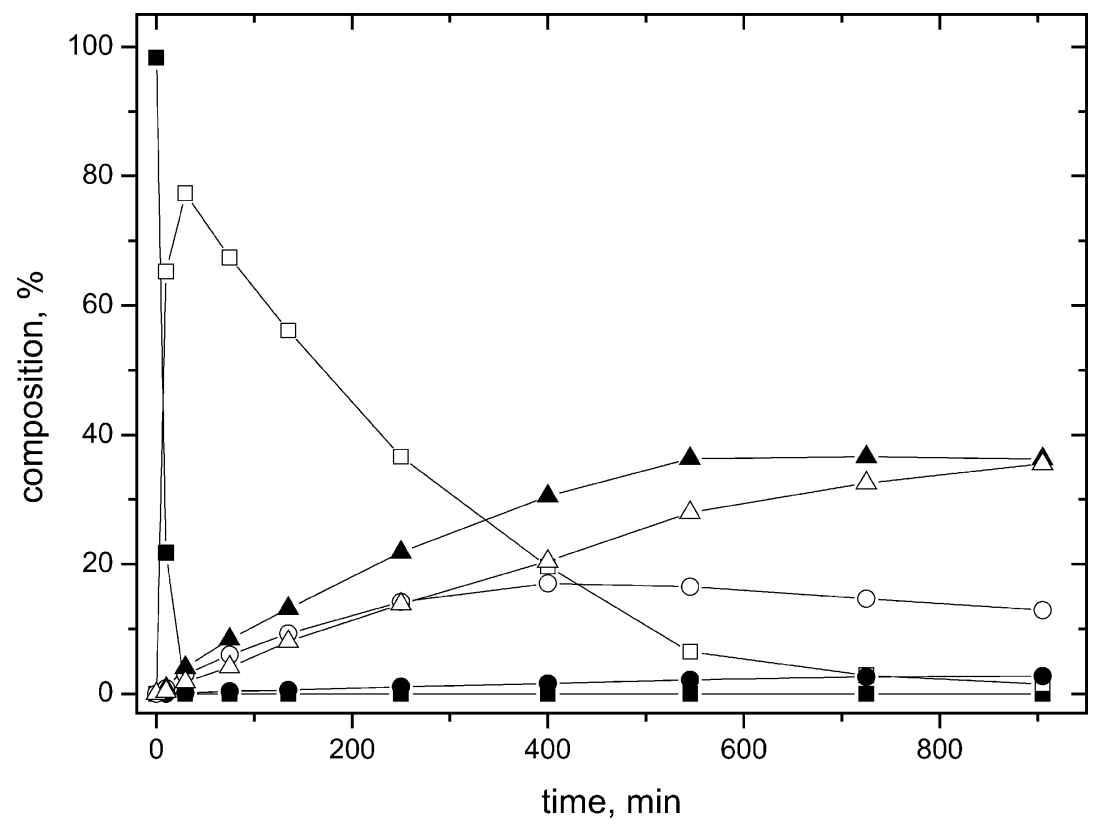

Fig. 2. Hydrodehalogenation of dieldrin over $\mathrm{Pd} / \mathrm{C} 5 \%$ with $\mathrm{H}_{2}$ in the $36 \%$ ethanolic $\mathrm{KOH}$ solution. $(\triangle): 4+7 ;(\mathbf{O}): 8$. 
1,2,3,4,7,7-hexachloronorborn-2-ene with $\mathrm{H}_{2}$ over $\mathrm{Pd} / \mathrm{C}$ in the presence of $\mathrm{Et}_{3} \mathrm{~N}$ or $\mathrm{KOH}$ in ethanol $[25,26]$, the bridge carbon chlorines are inert (as well as those at bridgehead carbons), while the ones at the double bond, including the latter, are reduced readily.

\subsection{Hydrodechlorination of dieldrin over Raney-Ni}

The reaction of dieldrin over Raney-Ni does not occur in ethanol with $\mathrm{KOH}$ (entry 3, Table 3). Nevertheless, in the multiphase system with $7 \%$ base and Aliquat 336 dieldrin undergoes quantitative conversion to 2 in 150 min (entry 1). The reaction over Raney-Ni, even though comparatively faster than with $\mathrm{Pd} / \mathrm{C}$ only when a 100 -fold excess of $\mathrm{Ni}$ is used, is of particular interest: firstly, because of the 100-fold lower cost of this catalyst, and secondly, because this activity of Raney-Ni is only due to the presence of Aliquat 336 in the system. No reaction was observed in the analogous system without Aliquat 336 (entry 2), as has been previously shown for $\mathrm{HDCl}$ of polychlorinated benzenes $[6,8]$. As before, the $\mathrm{HDCl}$ over Raney-Ni proceeded much slower in ethanol than in the multiphase system.

The reaction with Raney-Ni is also more selective than that with $\mathrm{Pd} / \mathrm{C}$. Only the products of mono- and bidechlorination are formed in sizeable amounts. The reduction of the second chlorine (in 2) is slower, and gives rise also to small amounts of by-products (further $\mathrm{HDCl}$ or reduction of other chlorines).

The product of reduction of two chlorines was isolated, and its structure was identified as that of 6 by COSY and NOESY NMR experiments. In the COSY spectrum presented in Fig. 3, the proton that substitutes a chlorine atom on the carbon bridge of dieldrin appears as a doublet at $\delta 4.1$. This proton gives a cross-peak with the proton at $\delta$ 3.15 , which is also a "new" proton in the dieldrin structure. The multiplet at $\delta 3.15$ corresponds to the proton at the bridgehead carbon of 6 (its also gives cross-peaks with a pair of $\mathrm{CH}$ protons at $4 \mathrm{a}$ and 8 a positions at $\delta 2.3$ ). Because of this "new proton", the structure of $\mathbf{6}$ no longer has the $\mathrm{C}_{\mathrm{s}}$ symmetry. This results in a more complexly resolved ${ }^{1} \mathrm{H}$ NMR spectrum of $\mathbf{6}$, while in the ${ }^{1} \mathrm{H}$ NMR spectra of $\mathbf{1}$ and $\mathbf{2}$, the three pairs of symmetric protons gave singlets (NMR of 2: 4.29 (s, 1H, 10-CHCl), 3.1 (s, 2H, 6-CH and 7-CH), 2.71 (s, $2 \mathrm{H}, 4 \alpha-\mathrm{CH}$ and $8 \alpha-\mathrm{CH}$ ), 2.47 (s, $2 \mathrm{H}, 5-\mathrm{CH}$ and $8-\mathrm{CH}$ ), 0.9-1.25 (dd, 2H, 9- $\mathrm{CH}_{2}$ ); NMR of 1: 3.13 (s, 2H, 6-CH and
7-CH), 2.71 (s, 2H, $4 \alpha-\mathrm{CH}$ and $8 \alpha-\mathrm{CH}$ ), 2.67 (s, 2H, 5-CH and $\left.8-\mathrm{CH}), 1.0-1.3\left(\mathrm{dd}, 2 \mathrm{H}, 9-\mathrm{CH}_{2}\right)\right)$. The geometry of the proton at the $\mathrm{CHCl}$ methane bridge in $\mathbf{6}$ (and therefore in $\mathbf{2}$ ) is evident from the NOESY spectrum where no throughspace interaction between this proton and the protons at $4 \mathrm{a}-$ and 8a-carbons was observed.

The selective reduction of a chlorine at the bridgehead carbon in the reaction of dieldrin over Raney-Ni is intriguing, since this proton is usually the most difficult to reduce. For example, according to the data of [26], where similar 1,2,3,4,7,7-hexachloronorborn-2-ene was studied in $\mathrm{Pd} / \mathrm{C}$ and Raney-Ni systems with hydrogen, the chlorines at bridgehead carbons never reduced. In fact, there is no such process of dieldrin or of similar structure reported, and compound 6 is unknown to the best of our knowledge. As it has been mentioned above, such a process would rather have a radical nature. However, it was proven that the removal of this chlorine is the true catalytic $\mathrm{HDCl}$, since no reaction occurred in the analogous system without catalyst, and only minimum conversion (around 5\%) was observed in the same system with Raney-Ni, but without hydrogen.

Contrarily to the reaction on $\mathrm{Pd} / \mathrm{C}$, dieldrin does not undergo $\mathrm{HDCl}$ over Raney-Ni in the ethanol-KOH system (entry 3 ), where only $1 \%$ conversion of the starting material was observed for $330 \mathrm{~min}$ of reaction.

\subsection{Hydrodechlorination of dieldrin over $5 \% \mathrm{Pt} / \mathrm{C}$}

Another different situation is observed in the reaction of $\mathbf{1}$ on $\% \mathrm{Pt} / \mathrm{C}$ (where the same metal - substrate molar ratio was respected). It is known that $\mathrm{Pt} / \mathrm{C}$ is not very efficient as catalyst for $\mathrm{HDCl}$ of polychlorinated aromatics, though it appears quite active for $\mathrm{HDCl}$ of aliphatic substrates, as we have previously shown in the reduction of lindane $(\gamma$ hexachlorocyclohexane) [7].

The reduction of dieldrin on $\mathrm{Pt} / \mathrm{C}$ appears less deep than that on Pd or Raney-Ni: only one chlorine of six can be removed (see Scheme 4). However, the $\mathrm{HDCl}$ on Pt proceeds with increased selectivity: only the products of mono-HDCl were detected, which were identified as $\mathbf{2}$ and $\mathbf{2 a}$, because of the identity of their MS spectra. The former was formed in seven-fold excess in the reaction without Aliquat 336 (entry 1, Table 4), and with almost quantitative yield in the presence of Aliquat 336 (entry 2). One sees from Table 4 that the reaction is rather sluggish without Aliquat 336, but is

Table 3

Hydrodechlorination of dieldrin over Raney-Ni in different systems with $7 \% \mathrm{KOH}^{\mathrm{a}}$

\begin{tabular}{|c|c|c|c|c|c|c|c|}
\hline \multirow[t]{2}{*}{ No. } & \multirow[t]{2}{*}{ Solvent } & \multirow[t]{2}{*}{ Aliquat 336} & \multirow[t]{2}{*}{ Time (min) } & \multirow[t]{2}{*}{ Conversion (\%) } & \multirow[t]{2}{*}{$X(\%)$} & \multicolumn{2}{|c|}{ Yield $(\%, \mathrm{GC})$} \\
\hline & & & & & & 2 & 6 \\
\hline 1 & Isooctane/toluene & Yes & $\begin{array}{r}150 \\
1800\end{array}$ & 100 & $\begin{array}{l}20 \\
36\end{array}$ & $\begin{array}{l}85 \\
10\end{array}$ & $\begin{array}{l}12 \\
71\end{array}$ \\
\hline 2 & Isooctane/toluene & No & 200 & 0 & 0 & 0 & 0 \\
\hline 3 & EtOH & No & 330 & 1 & 0 & 1 & 0 \\
\hline
\end{tabular}

${ }^{\mathrm{a}} 7 \%$ in ethanol or in $5.7 \mathrm{ml}$ aqueous solution. 


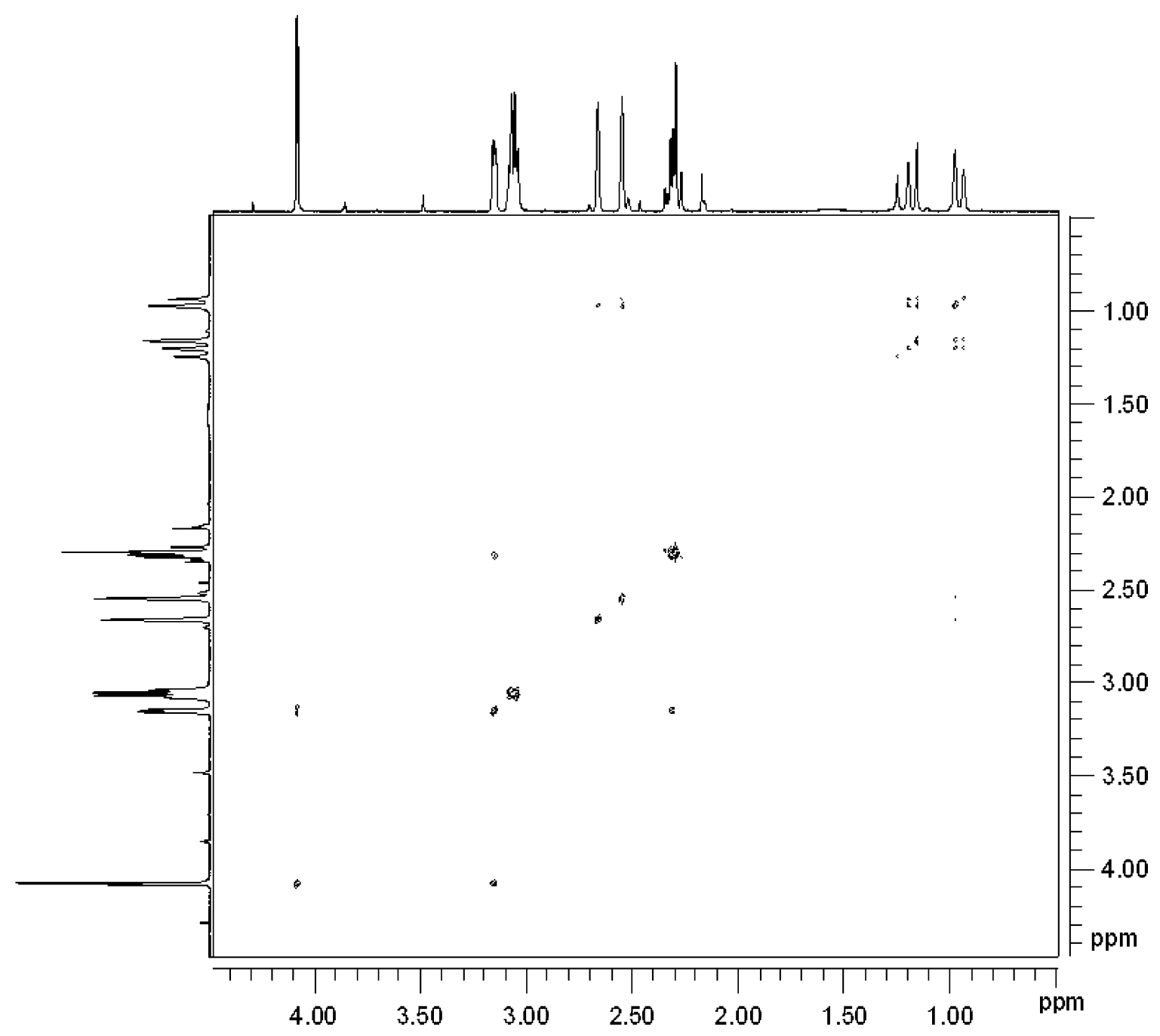

Fig. 3. NMR COSY spectrum of the product of two chlorine atoms reduction of dieldrin (6) acquired on Bruker 300.

complete (97\% yield of 2 ) in several minutes in the system with Aliquat 336.

\subsection{Hydrodechlorination of DDT over Pd/C and Raney-Ni in the multiphase system}

$\mathrm{HDCl}$ of DDT was studied over $5 \% \mathrm{Pd} / \mathrm{C}, 5 \% \mathrm{Pt} / \mathrm{C}$, and Raney-Ni catalysts in the biphasic reduction systems, composed of isooctane and aqueous phase where the effects of Aliquat 336 and $\mathrm{KOH}$ on the reaction have been studied. The composition of products at different time intervals in the reactions on $\mathrm{Pd} / \mathrm{C}$ with different system compositions are reported in Table 5. Similarly, the analogous results on other catalysts in the same systems are presented in Table 6. The number assigned to compounds in Tables 5 and 6 are those of Scheme 5, describing most common pathways of DDT (9) transformations in our systems.

One can note that there is no principal difference between the behavior of DDT on different catalysts as regards reaction pathways and selectivity. DDT undergoes complete dechlorination over Raney-Ni under mild conditions and in just $40 \mathrm{~min}$, whereas it requires almost $5 \mathrm{~h}$ on $\mathrm{Pd} / \mathrm{C}$.
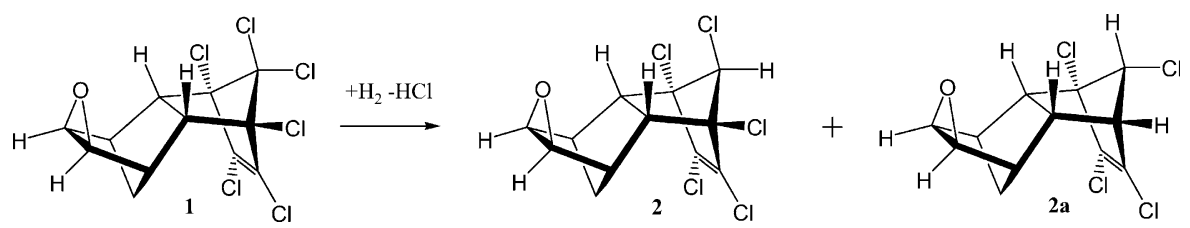

Scheme 4. Hydrodechlorination of dieldrin over Pt/C. 
Table 4

Hydrodechlorination of dieldrin over $5 \% \mathrm{Pt} / \mathrm{C}$ in the multiphase system with $7 \%$ aqueous $\mathrm{KOH}$

\begin{tabular}{|c|c|c|c|c|c|c|}
\hline \multirow[t]{2}{*}{ No. } & \multirow[t]{2}{*}{ Aliquat 336} & \multirow[t]{2}{*}{ Time (min) } & \multirow[t]{2}{*}{ Conversion $(\%)$} & \multirow[t]{2}{*}{$X(\%)$} & \multicolumn{2}{|c|}{ Yield (\%, GC/MS) } \\
\hline & & & & & 2 & $2 \mathbf{a}$ \\
\hline \multirow[t]{2}{*}{1} & No & 45 & 66 & 11 & 57 & 10 \\
\hline & & 520 & 97 & 16 & 85 & 12 \\
\hline 2 & Yes & 27 & 100 & 17 & 97 & 3 \\
\hline
\end{tabular}

In all systems where both $\mathrm{KOH}$ and Aliquat 336 are present, the first reaction step is the base promoted dehydrochlorination at the aqueous organic interface leading to formation of DDE (10) (entry 1 of Tables 5 and 6 and entry 3 of Table 6). This process gives selectively DDE in just $5 \mathrm{~min}$ if catalyzed by Aliquat 336, where the latter acts as a phase transfer catalyst [7]. In case if there is no Aliquat 336 in the system, or in the absence of $\mathrm{KOH}$, dehydrochlorination is slow, and therefore no or small amounts of DDE are formed.

In the system with Aliquat 336 and $\mathrm{KOH}$, DDE as formed then undergoes reduction of its two aliphatic chlorines, giving right away $\mathbf{1 4}$. The intermediate $\mathbf{1 1}$ is formed in small quantities and there is no other intermediate observed in the mixture before 14. This is probably indicative of very high reaction rate of the double bond. Considering other experiments of DDT reported in Tables 5 and 6 where there was DDE (10) as intermediate, one can note that $\mathbf{1 1}$ was detected occasionally and as a rule in low quantities, which tells that reduction of both chlorines in 10 is fast and that of the double bond is even faster. The reason of such concerted reaction of double bond and two chlorines could be that all these groups lie in the same plane and, once adsorbed on the active site, are disposed to the reaction to the same extent. From all evidence, the reduction of the double bond takes place the last, since the chlorines create a hindering effect. A similar behavior was observed in the reaction of dieldrin discussed below, where the double bond with two chlorines at its different parts also did not reduce before dechlorination.
One can note that in cases where either $\mathrm{KOH}$ or Aliquat 336 are missing (entries 2, 3 of Table 5 and entry 2 of Table 6) DDE (10) is not formed, or formed at low concentrations. Instead, in such systems, where dehydrochlorination is not favored, another intermediate, DDD (12) is predominantly formed. DDD is formed via $\mathrm{HDCl}$ on metal catalyst of one of three aliphatic chlorines in DDT. This process is slower than dehydrochlorination. However, $\mathbf{1 3}$ was never observed in the reaction mixture which tells that the reduction of the last aliphatic chlorine occurs with high rate. The reaction pathway through DDD, i.e. 9-12-13-14 again gives 14 in the end. As $\mathbf{1 4}$ is formed, the advantage of the multiphase system with Aliquat 336 and $\mathrm{KOH}$ before the other ones become evident: only in the presence of these two components we managed to achieve full dechlorination with quantitative formation of $\mathbf{1 6}$, which is due to the known fact that the co-presence of Aliquat 336 and $\mathrm{KOH}$ produces a strong promoting effect on the HDC of aromatic chlorine [68]. In the other systems, the mixture of $\mathbf{1 6}$ partial dechlorination products $\mathbf{1 4}$ and $\mathbf{1 5}$ was formed at long reaction times, e.g. in the reaction over Raney-Ni which exhibits more activity, the conversion to $\mathbf{1 6}$ reached only $58 \%$ after $650 \mathrm{~min}$ reaction time.

In the system on $\mathrm{Pt} / \mathrm{C}$ (entry 3 of Table 6), even in presence of $\mathrm{KOH}$ and Aliquat 336, the reaction is the most sluggish and less selective. The presence of 1,1'-bis-(4chlorophenyl)ethane and 1-(4-chlorophenyl)-1-phenylethene indicates low rate of the double bond hydrogenation in this case, whereas this was always the fastest process in other systems. $\mathrm{HDCl}$ of aromatic chlorines is also slow as only $3 \%$ of 16 is formed after $3 \mathrm{~h}$ reaction time.

Table 5

Hydrodechlorination of DDT over $5 \% \mathrm{Pd} / \mathrm{C}$ in the biphasic isooctane-aqueous system

\begin{tabular}{|c|c|c|c|c|c|c|c|c|c|c|c|c|}
\hline \multirow[t]{2}{*}{ No. } & \multirow[t]{2}{*}{ Aliquat 336} & \multirow[t]{2}{*}{$\mathrm{KOH}(\%)$} & \multirow[t]{2}{*}{ Time (min) } & \multirow[t]{2}{*}{ Conversion (\%) } & \multirow[t]{2}{*}{$X(\%)$} & \multicolumn{7}{|c|}{ Yield (\%, GC) } \\
\hline & & & & & & 10 & 11 & 12 & 14 & 15 & 16 & Other \\
\hline \multirow[t]{3}{*}{1} & \multirow[t]{3}{*}{ Yes } & \multirow[t]{3}{*}{7} & 5 & \multirow[t]{3}{*}{100} & 20 & 100 & 0 & 0 & 0 & 0 & 0 & 0 \\
\hline & & & 40 & & 33 & 76 & 3 & 0 & 5 & 12 & 4 & 0 \\
\hline & & & 290 & & 100 & 0 & 0 & 0 & 0 & 0 & 100 & 0 \\
\hline \multirow[t]{3}{*}{2} & \multirow[t]{3}{*}{ No } & \multirow[t]{3}{*}{7} & 130 & 82 & 46 & 0 & 0 & 10 & 70 & 1 & 1 & 0 \\
\hline & & & 190 & 100 & 60 & 0 & 0 & 5 & 88 & 5 & 2 & 0 \\
\hline & & & 300 & & 65 & 0 & 0 & 0 & 81 & 15 & 4 & 0 \\
\hline \multirow[t]{2}{*}{3} & \multirow[t]{2}{*}{ Yes } & \multirow[t]{2}{*}{0} & 90 & 100 & 60 & 8 & 0 & 11 & 50 & 25 & 3 & 0 \\
\hline & & & 450 & & 85 & 0 & 0 & 0 & 12 & 25 & 40 & $14^{\mathrm{a}} / 7^{\mathrm{b}}$ \\
\hline
\end{tabular}

\footnotetext{
a 1,1-Dichloro-2,2-diphenylethane.
}

b diphenylmethane. 
Table 6

Hydrodechlorination of DDT over Raney-Ni in the biphasic isooctane-aqueous system

\begin{tabular}{|c|c|c|c|c|c|c|c|c|c|c|c|c|}
\hline \multirow[t]{2}{*}{ No. } & \multirow[t]{2}{*}{ Aliquat 336} & \multirow[t]{2}{*}{$\mathrm{KOH}(\%)$} & \multirow[t]{2}{*}{ Time (min) } & \multirow[t]{2}{*}{ Conversion (\%) } & \multirow[t]{2}{*}{$X(\%)$} & \multicolumn{7}{|c|}{ Yield $(\%, \mathrm{GC})$} \\
\hline & & & & & & 10 & 11 & 12 & 14 & 15 & 16 & Other \\
\hline \multirow[t]{2}{*}{1} & Yes & 7 & 5 & 100 & 53 & 45 & 2 & 0 & 4 & 39 & 12 & 0 \\
\hline & & & 40 & & 100 & 0 & 0 & 0 & 0 & 0 & 100 & 0 \\
\hline \multirow[t]{3}{*}{2} & No & 7 & 15 & 86 & 26 & 0 & 11 & 58 & 17 & 0 & 0 & 0 \\
\hline & & & 60 & 100 & 64 & 0 & 0 & 0 & 80 & 19 & 2 & 0 \\
\hline & & & 650 & & 92 & 0 & 0 & 0 & 0 & 42 & 58 & 0 \\
\hline \multirow[t]{2}{*}{$3^{\mathrm{a}}$} & Yes & 7 & 5 & 100 & 20 & 100 & 0 & 0 & 0 & 0 & 0 & 0 \\
\hline & & & 180 & & 56 & 21 & 0 & 0 & 26 & 9 & 3 & $29^{b} / 13^{c}$ \\
\hline
\end{tabular}

${ }^{a} \% \mathrm{Pt} / \mathrm{C}$ as catalyst.

b 1,1'-Bis-(4-chlorophenyl)ethane.

c 1-(4-Chlorophenyl)-1-phenylethene.<smiles>C=CC(C)c1ccc(C(C)c2ccc(Cl)cc2)cc1</smiles>

Scheme 5. DDT dechlorination pathways in reduction systems.

\section{Conclusions}

Partial HDCl of dieldrin with hydrogen in the multiphase system or in EtOH can be achieved over the catalysts such as $5 \% \mathrm{Pd} / \mathrm{C}, 5 \% \mathrm{Pt} / \mathrm{C}$, or Raney-Ni at atmospheric pressure and $50{ }^{\circ} \mathrm{C}$. The reaction, that proceeds with different selectivity and degree of dechlorination depending on the choice of catalyst, system, and base concentration, requires always the presence of base (aqueous $\mathrm{KOH}$ in the multiphase system or dissolved in $\mathrm{EtOH}$ ) and is always favored by the presence of Aliquat if run in the multiphase system, which acts as a promoter of $\mathrm{HDCl}$. No other than $\mathrm{HDCl}$ processes (e.g. reduction of epoxy function) was observed.

In all the systems studied, the first dechlorination step is that of the reduction of the syn-chlorine atom on the bridge carbon. The corresponding mono-dechlorination product can be obtained with very high yields (more than 90\%) in short reaction times.
Further $\mathrm{HDCl}$ of dieldrin on $\mathrm{Pd} / \mathrm{C}$ in the multiphase system involves the reduction of a pair of chlorines at the double bond and reduction of the double bond, as well as the reduction of the second chlorine at the bridge carbon, which leads to the formation of a mixture of partial dechlorination products. Reduction of dieldrin on $\mathrm{Pd} / \mathrm{C}$ in the presence of concentrated $\mathrm{KOH}$ in the multiphase system or in the ethanolic $\mathrm{KOH}$ system is deeper but still less selective. In this case, the $\mathrm{HDCl}$ of a chlorine atom at the bridgehead carbon appears possible.

Reduction of dieldrin over Raney-Ni appears possible only in the multiphase system (no reaction in the EtOH-KOH system) and proceeds mainly via two dechlorination steps, where the reduction of syn-chlorine atom on the bridge carbon is followed by slower reduction of the chlorine at the bridgehead carbon with nearly $80 \%$ selectivity towards the corresponding bi-dechlorination

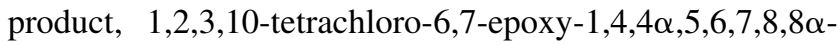


octahydro-1,4-endo,exo-5,8-dimethanonaphthalene, not previously reported, which was separated and characterized by COSY and NOESY NMR.

In the multiphase system 5\% Pt/C dieldrin undergoes removal of one chlorine only, giving a mix of two monodechlorination products, corresponding to the reduction of syn- and anti-chlorine atoms on the bridge carbon, where the former is dominating (especially in the system with Aliquat 336).

Reduction of DDT over Pd/C, Pt/C or Raney-Ni usually follows one of two general dechlorination pathways in the biphasic aqueous organic medium depending on the presence of $\mathrm{KOH}$ and Aliquat 336 in the system, namely 9-10-11-14-15-16 or 9-12-13-14-15-16 (Scheme 5), where the former pathway takes place in their presence and the latter one does if one of them is absent.

In both cases, the aromatic chlorines react after the reduction of aliphatic ones. In the basic system with Aliquat 336 , the aliphatic chlorines undergo very fast base promoted dehydrochlorination to DDE (10) (Aliquat 336 acts as a phase transfer agent) which is then followed by the HDCl of two remaining chlorines and the double bond hydrogenation. In the system where $\mathrm{KOH}$ or Aliquat 336 is absent, all three aliphatic chlorines of DDT undergo HDCl.

The most selective and complete $\mathrm{HDCl}$ was observed in the systems with $\mathrm{Pd} / \mathrm{C}$ and Raney-Ni containing both Aliquat 336 and $\mathrm{KOH}$, where besides easier dechlorination of aliphatic chlorines (thanks to the phase-transfer effect by Aliquat 336) the reduction of the aromatic chlorines is also favored, since Aliquat 336 is known to act as a promoter of $\mathrm{HDCl}$ of aromatic chlorine. In the same system with $\mathrm{Pt} / \mathrm{C}$ instead the reaction is slowest since neither reduction of the double bond nor that of aromatic chlorine is favored on this catalyst.

\section{Acknowledgments}

We would like to acknowledge the support of the Italian Ministry of Foreign Affairs, the Italian Interuniversity Consortium "Chemistry for the Environment" (INCA) (Piano "Ambiente Terrestre: Chimica per l'Ambiente", Legge 488/92, Project No. 6), and Ca' Foscari University of Venice.

\section{References}

[1] X. Ram, http://www.chem.unep.ch/pops/newlayout/repdocs.html.

[2] F. Alonso, I.P. Beletskaya, M. Yus, Chem. Rev. 102 (2002) 4009-4092; V.V. Lunin, E.S. Lokteva, Russ. Chem. Bull. 45 (1996) 1609-1624;
F.J. Urbano, J.M. Marinas, J. Mol. Catal. A: Chem. 173 (2001) 329345.

[3] J.H. Hoke, G.A. Gramiccioni, E.N. Balko, J. Appl. Catal. B 1 (1992) 285-296;

M.A. Aramendía, V. Borau, I.M. García, C. Jiménez, A. Marinas, J.M. Marinas, F.J. Urbano, C. R. Acad. Sci. Paris, Série Ilc, Chim./Chem. (2000) 465-470

[4] C.D. Thompson, R.M. Rioux, M. Chen, F.H. Ribeiro, J. Phys. Chem. B. 104 (2000) 3067-3077;

S. Ordóñez, F.V. Díez, H. Sastre, Ind. Eng. Chem. Res. 41 (2002) 505511 ;

P. Forni, L. Prati, M. Rossi, J. Appl. Catal. B 14 (1997) 49-53;

G. Tavoularis, M.A. Keane, J. Mol. Catal. A: Chem. 142 (1999) $187-$ 199.

[5] P. Tundo, S. Zinovyev, A. Perosa, J. Catal. 196 (2000) 330; A. Perosa, P. Tundo, S. Zinovyev, Green Chem. 4 (2002) 492;

A. Perosa, P. Tundo, M. Selva, J. Mol. Catal. A 180 (2002) 169; A. Bomben, C.A. Marques, M. Selva, P. Tundo, Synthesis (1996) 1109.

[6] C.A. Marques, O. Rogozhnikova, M. Selva, P. Tundo, J. Mol. Catal. A: Chem. 96 (1995) 301;

S. Zinovyev, A. Perosa, S. Yufit, P. Tundo, J. Catal. 211 (2002) 347.

[7] S.S. Zinovyev, N.A. Shinkova, A. Perosa, P. Tundo, J. Appl. Catal. B 47 (2004) 27.

[8] C.A. Marques, M. Selva, P. Tundo, J. Org. Chem. 58 (1993) 5256.

[9] C.A. Marques, M. Selva, P. Tundo, J. Org. Chem. 59 (1994) 3830.

[10] A. Perosa, M. Selva, P. Tundo, S.S. Zinovyev, Appl. Catal. B 32 (2001) L1.

[11] P. Durea, S.K. Mukerjee, Tetrahedron Lett. 26 (1985) 5211-5212; H.G. Nagl, W. Klein, F. Korte, Tetrahedron 26 (1970) 5319-5325.

[12] A. Kubátová, A.J.M. Lagadec, S.B. Hawthorne, Environ. Sci. Technol. 36 (2002) 1337.

[13] C.H.M. Adams, K. Mackenzie, J. Chem. Soc. C (1969) 480-486.

[14] T. Svensson, S. Winstein, J. Am. Chem. Soc. 94 (1972) 2336 2347.

[15] Toxicological Profile for DDT, DDE, and DDD, US Department of Health and Human Services, Public Health Service, Agency for Toxic Substances and Disease Registry, 2002, http://www.atsdr.cdc.gov/ toxprofiles/tp35.pdf.

[16] J. Gao, A.W. Garrison, C. Hoehamer, C.S. Mazur, N.L. Wolfe, J. Agric. Food Chem. 48 (2000) 6121.

[17] J. Foght, T. April, K. Biggar, J. Aislabie, Bioremediat. J. 5 (2001) 225.

[18] M.D. Engelmann, J.G. Doyle, I.F. Cheng, Chemosphere 43 (2001) 195.

[19] S. Schweizer, J.F. Rusling, Q. Huang, Chemosphere 28 (1994) 961.

[20] A. Galadi, H. Bitar, M. Chanon, M. Julliard, Chemosphere 30 (1995) 1655 .

[21] Allied Chem. \& Dye Corp., US 2,793,237 (1953); M.A. Pasha, D. Nagaraja, Ind. J. Chem. Sect. B 41 (2002) 1747.

[22] A.H. Weiss, R.B. LaPierre, Acta Chim. Acad. Sci. (Hung.) 103 (1980) $111-121$.

[23] D. Bieniek, P.N. Moza, W. Klein, K. Korte, Tetrahedron Lett. 47 (1970) 4055-4058.

[24] T. Tanuma, K. Ohnishi, H. Okamoto, T. Miyajima, S. Morikawa, J. Fluorine Chem. 57 (1992) 259-284.

[25] A.P. Marchand, W.R. Weimar, J. Org. Chem. 34 (1969) 11091112.

[26] C.K. Alden, D.I. Davies, J. Chem. Soc. C (1968) 700-704. 